\title{
Adherence to COVID-19 preventive measures among dental care workers in Vietnam: an online cross-sectional survey
}

\section{Tai Tan Tran}

Faculty of Odonto-Stomatology, University of Medicine and Pharmacy, Hue University, Hue city 530000, Vietnam https://orcid.org/0000-0002-4743-512X

\section{Thang Van Vo}

Institute for Community Health Research, University of Medicine and Pharmacy, Hue University, Hue city 530000, Vietnam Faculty of Public Health, University of Medicine and Pharmacy, Hue University, Hue city 530000, Vietnam https://orcid.org/0000-0003-2018-0371

\section{Tuyen Dinh Hoang}

Institute for Community Health Research, University of Medicine and Pharmacy, Hue University, Hue city 530000, Vietnam Faculty of Public Health, University of Medicine and Pharmacy, Hue University, Hue city 530000, Vietnam https://orcid.org/0000-0002-9725-4212

\section{Minh Vu Hoang}

Faculty of Odonto-Stomatology, University of Medicine and Pharmacy, Hue University, Hue city 530000, Vietnam https://orcid.org/0000-0003-4239-6165

\section{Nhu Thi Quynh Tran}

Faculty of Odonto-Stomatology, University of Medicine and Pharmacy, Hue University, Hue city 530000, Vietnam https://orcid.org/0000-0002-0219-8861

\section{Robert Colebunders ( $\square$ robert.colebunders@uantwerpen.be )}

Global Health Institute, University of Antwerp, Antwerp 2000, Belgium https://orcid.org/0000-00021919-1340

\section{Research Article}

Keywords: Dental care workers, COVID-19 prevention measures, adherence, quality of life.

Posted Date: December 13th, 2021

DOI: https://doi.org/10.21203/rs.3.rs-1160815/v1

License: (c) (i) This work is licensed under a Creative Commons Attribution 4.0 International License. Read Full License 
Version of Record: A version of this preprint was published at International Journal of Environmental Research and Public Health on January 2nd, 2022. See the published version at https://doi.org/10.3390/ijerph19010481. 


\section{Adherence to COVID-19 preventive measures among dental care}

\section{2 workers in Vietnam: an online cross-sectional survey}

3 Tai Tan Tran ${ }^{1}$, Thang Van Vo ${ }^{2,3}$, Tuyen Dinh Hoang ${ }^{2,3}$, Minh Vu Hoang ${ }^{1}$, Nhu Thi Quynh

$4 \operatorname{Tran}^{1}$, Robert Colebunders ${ }^{4 *}$

\section{Affiliations}

6 1. Faculty of Odonto-Stomatology, University of Medicine and Pharmacy, Hue University, Hue 7 city 530000, Vietnam

8 2. Institute for Community Health Research, University of Medicine and Pharmacy, Hue

9 University, Hue city 530000, Vietnam

10 3. Faculty of Public Health, University of Medicine and Pharmacy, Hue University, Hue city

11530000, Vietnam

12 4. Global Health Institute, University of Antwerp, Antwerp 2000, Belgium

\section{*Corresponding author}

\section{Robert Colebunders}

Email: robert.colebunders@uantwerpen.be

ORCID: 0000-0002-1919-1340

\section{Abstract}

An online cross-sectional survey using a "snowball" sampling method was carried out to assess the adherence to COVID-19 preventive measures among dental care workers (DCWs) during the pandemic. Six questions concerning the COVID-19 preventive guidelines issued by the Vietnam Ministry of Health were used to evaluate DCWs adherence to preventive measures at dental care clinics. The quality of life of DCWs was assessed using the WHO-5 questionnaire and was defined as low if the total score was less than 13 points. Factors relating to adherence to COVID-19 
25 prevention measures of DCWs were determined by multivariate linear regression analysis. In total, 26514 DCWs completed the questionnaire. 37\% DCWs rated their quality of life as low. Regression 27 analysis suggested that older age, better quality of life, living in an urban area, and training on 28 COVID-19 prevention were associated with better adherence to COVID-19 preventive measures, 29 while being a dentist and lack of personal protective equipment was associated with less adherence 30 to COVID-19 preventive measures. The pandemic had a significant negative impact on the 31 physical and mental health of DCWs. Therefore, specific national guidelines for the prevention 32 and control of the spread of COVID-19 in dental facilities should be issued.

34 Keywords: Dental care workers, COVID-19 prevention measures, adherence, quality of life. 


\section{Introduction}

37 The World Health Organization (WHO) declared COVID-19 as a global pandemic on March 11, 382020 due to its alarming spread and severity [1]. Until November 28, 2021, the total number of 39 confirmed COVID-19 cases in the world was at 260,493,573, of which 5,195,354 people died [2]. Since the first reported case of domestic infection, Vietnam has experienced 4 waves of the COVID-19 pandemic spreading. On October 3, 2021, there were over 939,463 cases and 22,283 deaths nationwide [3]. The appearance of the COVID-19 Delta variant caused a large-scale spread of the disease in Ho Chi Minh city and other provinces [3]. The COVID-19 pandemic had a severe impact on various professions in society, especially dental care workers (DCW) who were directly exposed to the COVID-19 virus at medical facilities.

According to a WHO report in September 2021, only 6,643 healthcare workers (HCWs) were reported to have died of COVID-19 [4]. However, WHO estimated that this number of deaths among HCWs is much larger than officially reported, and is possibly over 180,000 people. Therefore, increasing the efforts to protect HCW through COVID-19 vaccination should be a top priority, especially in countries with low vaccination rates among HCWs and high vaccination hesitancy [4].

The high risk of infection among HCWs is caused by close contact with patients diagnosed with COVID-19, but also with undiagnosed cases of COVID-19. Lack of personal protective equipment (PPE) increases this risk [5,6]. In addition to physical health impacts, the COVID-19 pandemic also had a huge impact on the mental health of medical staff, causing depression, anxiety and insomnia [7]. A study in Da Nang city, during the second wave of this pandemic, showed an increase in the prevalence of stress among frontline HCWs [8].

Vietnam has a large number of skilled dentists that contribute to international dental tourism because they offer quality dental care at an affordable cost. These dental care services provide many standard treatment technologies such as orthodontic treatment, implants, porcelain crowns, 
61 bridges, dentures, fillings, root canal, tooth extraction, and full mouth restoration etc. The current

62

63

64

65

66

67

68

69 number of DCWs in Vietnam is unknown but in 2013, it was estimated that there were 608 dentists, and 203 dental technicians in Vietnam. DCWs are at high risk of infection during dental procedures because they are in direct contact with aerosols and droplets from patients [9-11]. Therefore, adherence to infection control procedures is essential [12]. According to the WHO COVID-19 guidelines for HCWs, the prevention of dental problems and self-care should be a top priority [13]. Patients should receive dental advice through teleconsultations and social media need to promote good oral hygiene [13]. The American Dental Association has released interim guidelines to minimize the risk of COVID-19 infection before, during, and after dental treatment [14]. The Vietnam Ministry of Health $(\mathrm{MoH})$ issued a general guideline for the prevention and control of COVID-19 infection in medical facilities [15,16]. However, in Vietnam, there is currently no specific guideline for COVID-19 prevention and control for dental care services. According to WHO recommendations, periodical dental check-ups should be postponed, while dental emergencies and treatment still need to be performed with adequate safety measures. In this study we assessed the adherence of DCWs to COVID-19 preventive measures and the impact of the pandemic on the quality of life of DCWs.

\section{Materials and Methods}

\subsection{Study design}

A cross-sectional online survey was conducted among DCWs across Vietnam from August $21^{\text {st }}$ to September $9^{\text {th }}, 2021$.

\subsection{Study procedures}

Sample size and sampling method: Sampling was done using a snow-ball approach: persons who completed the online questionnaire were encouraged to share the survey web link with their personal contacts in all dental care services in the country. We tried to reach as many DCWs as possible during a twenty-day period. All eligible entries recorded within this period were included 
in the study. Five hundred twenty five DCWs responded to the survey but nine did not agree to

87 participate in the study and in two the answers were incomplete. Therefore only $514(97.9 \%)$

88

89

90

91

92

93

94

95 responses were included in the data analysis.

Factors considered to be possibly related to adherence to preventive measures included: sociodemographic characteristics, knowledge and skills on COVID-19 prevention, and impact of COVID-19 on the lives of DCWs (Figure 1).

\section{Impact of COVID-19 on the lives of DCWs}

Fears and worry about the DCWs health as well as their relatives' health were measured on a 5point Likert scale $(1=$ not worried/afraid, to $5=$ extremely worried/afraid) [17]. The impact of the COVID-19 pandemic on DCWs income was measured on a 5-point Likert scale from $1=$ not reduced to $5=$ extremely reduced. Change in working time was measured on a 5-point Likert scale from $1=$ working time reduced a lot to $5=$ working time increased a lot. Difficulty in accessing food and food resources in the past week was measured on a 5-point Likert scale from $1=$ not difficult at all to $5=$ extremely difficult. Being stigmatized or discriminated by people due to working in an environment with a high risk of infection with the COVID-19 virus was measured on a 5-point Likert scale from $1=$ never to $5=$ very regularly. Quality of life of DCWs was assessed using the World Health Organization (WHO-5) 5-questions assessment tool over the past two weeks: "I have felt cheerful and in good spirits", "I have felt calm and relaxed", "I have felt active and vigorous", "I woke up feeling fresh and rested", "My daily life has been filled with things that interest me". Each question was scored from $0=$ never to $5=$ full time. Quality of life was scored on a scale from 0 to 25 points, where 0 was the lowest quality of life level and 25 was the highest quality of life level. A low quality of life was defined as a score below 13 points [18,19]. Adherence to COVID-19 preventive measures

As preventive measures we took into account the guidelines of the Vietnam $\mathrm{MoH}$ on prevention and control COVID-19 in medical facilities (decision No.5188/QD-BYT) [15]. Adherence to 
111 preventive measures was assessed using 6 questions, covering the following aspects: wearing PPE,

112 correct use of face masks during patient care, regular hand hygiene, cleaning and disinfection of

113 surfaces during patient care, safe disposure of waste, and other procedures to prevent transmission

114 of patient's saliva, blood and other body fluids. The response to each question was scored from 0

115 points $=$ never to 4 points $=$ always, and a total score was calculated (maximum score 24 points).

116 Additionally, we asked participants to self-evaluate how difficult it was to adhere to these

117 preventive measures, and this was also reported using a 5-point Likert scale $(1=$ not difficult at

118 all, to $5=$ extremely difficult).

Socio-demographic characteristics of participants

Age, gender, education level, profession, marital status, religion, place of residence, working place.

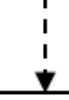

Knowledge and skills on Covid-19 prevention Trained in COVID-19 infection prevention skills, access to COVID-19 information, COVID-19 vaccination status and willingness.

\section{Impact of COVID-19 on DCWs}

Fear and worry about respondents' health or their relatives' health, decreasing income, changing working times, difficulties in obtaining food, being stigmatized or discriminated by surrounding people, quality of life. 


\subsection{Data analysis}

124 IBM SPSS software version 20.0 was used for statistical analysis. Continuous variables were

125 reported as means with standard deviation (SD), while categorical variables appeared as

126 percentages. A multivariable linear regression model was used to identify factors associated with

127 adherence to COVID-19 preventive measures.

\section{3. Results}

\section{3.1. Characteristics of participants}

130 Of the 514 respondents, $222(43.2 \%)$ were male, and $292(56.8 \%)$ female (Table 1$)$. The mean age was 33 years \pm 8 years. Most DCWs had undergraduate $(94.1 \%)$ and postgraduate education

$132(78 \%)$. About $80 \%$ of DCWs lived in an urban area and $88.1 \%$ worked in public hospitals and 133 private clinics.

135 Table 1. Characteristic of participants $(n=514)$

\begin{tabular}{|c|c|c|c|}
\hline \multicolumn{2}{|c|}{ Characteristic } & n & $\%$ \\
\hline \multicolumn{2}{|c|}{ Age $($ mean \pm SD) } & \multicolumn{2}{|c|}{$33 \pm 8$} \\
\hline \multicolumn{2}{|c|}{$\operatorname{Min}-\operatorname{Max}$} & \multicolumn{2}{|c|}{$22-62$} \\
\hline \multirow{2}{*}{ Gender } & Male & 222 & 43.2 \\
\hline & Female & 292 & 56.8 \\
\hline \multirow{3}{*}{ Education level } & High school & 30 & 5.9 \\
\hline & Undergraduate & 287 & 55.8 \\
\hline & Postgraduate & 197 & 38.3 \\
\hline \multirow{3}{*}{ Profession } & Dentist & 401 & 78.0 \\
\hline & Nurse & 89 & 17.3 \\
\hline & Technician & 16 & 3.1 \\
\hline
\end{tabular}




\begin{tabular}{|c|c|c|c|}
\hline & Other & 8 & 1.6 \\
\hline \multirow{5}{*}{ Marital status } & Single & 208 & 40.5 \\
\hline & Married & 294 & 57.2 \\
\hline & Divorced & 7 & 1.4 \\
\hline & Separated & 3 & 0.6 \\
\hline & Widow & 2 & 0.4 \\
\hline \multirow{3}{*}{ Religion } & No religion & 415 & 80.7 \\
\hline & Buddhism & 58 & 11.3 \\
\hline & Roman Catholicism & 41 & 8.0 \\
\hline \multirow{2}{*}{ Place of residence } & Urban & 418 & 81.3 \\
\hline & Sub-urban/ Rural & 96 & 18.7 \\
\hline \multirow{4}{*}{ Working place } & Public hospital & 244 & 47.5 \\
\hline & Private hospital & 43 & 8.4 \\
\hline & Private clinic & 209 & 40.6 \\
\hline & Other & 18 & 3.5 \\
\hline
\end{tabular}

137 3.2. Training and source of information about COVID-19 infection

138 Three hundred fifty three DCWs (68.7\%) received training to improve their knowledge and skills

139 to prevent COVID-19 infection (Table 2). The training content included, updates on the epidemic

140 situation, transmission routes and measures to prevent COVID-19 infection, how to assess and 141 identify risk factors for COVID-19 infection, clinical COVID-19 manifestations, how to

142 determine the COVID-19 infection status, and isolation regulations related to COVID-19. Main 143 information sources included television and radio $(81.5 \%)$, the website of the $\mathrm{MoH}(81.3 \%)$, and 144 the social media (86.8\%) (Table 2). 
Table 2. Training and source of information about COVID-19 prevention

\begin{tabular}{|l|l|c|c|}
\hline \multicolumn{2}{|c|}{ Knowledge and skills to prevent COVID-19 infection } & n & \% \\
\hline \multirow{4}{*}{ Has been trained to improve } & Yes & $353 / 514$ & 68.7 \\
\cline { 2 - 4 } their knowledge, skills to & & & \\
\hline \multirow{4}{*}{ prevent COVID-19 infection } & No & $161 / 514$ & 31.3 \\
\hline \multirow{4}{*}{ information about COVID- } & Television, radio & $419 / 514$ & 81.5 \\
\cline { 2 - 4 } & Website of the MoH & $418 / 514$ & 81.3 \\
\cline { 2 - 4 } & Electronic media & $392 / 514$ & 76.3 \\
\cline { 2 - 4 } & Social media & $446 / 514$ & 86.8 \\
\cline { 2 - 4 } & Relatives, friends, colleagues & $394 / 514$ & 76.7 \\
\cline { 2 - 4 } & Other & $8 / 514$ & 1.6 \\
\hline
\end{tabular}

\subsection{COVID-19 vaccination among dental care workers}

150 Three hundred ninety (75.0\%) DCWs received at least one dose of COVID-19 vaccine but 124

$151(24.1 \%)$ were not yet vaccinated. Of those not yet vaccinated, 65 (52.4\%) were willing to get

152 vaccinated with any type of COVID-19 vaccine while 50 (40.3\%) only accepted the vaccine they 153 considered the best (Table 3).

Table 3. COVID-19 vaccination among dental care workers

\begin{tabular}{|l|l|c|c|}
\hline \multirow{3}{*}{ Received at least one } & Vaccinated & $390 / 514$ & 75.9 \\
\cline { 2 - 4 } vaccine & & $124 / 514$ & 24.1 \\
& Not vaccinated yet & & \\
& Yes, with any type of vaccine & 65 & 52.4 \\
\cline { 2 - 4 } & Yes, but only with the best vaccine & 50 & 40.3 \\
\hline
\end{tabular}




\begin{tabular}{|l|l|c|c|}
\hline \multirow{4}{*}{ Willingness to be } & $\begin{array}{l}\text { Do not want vaccination due to health } \\
\text { problems }\end{array}$ & 6 & 4.8 \\
\cline { 2 - 4 } & Do not want vaccination due to fear that the & 1 & 0.8 \\
& vaccine will affect their health. & & \\
\cline { 2 - 4 } & Other & 2 & 1.6 \\
\hline
\end{tabular}

156

\subsection{Adherence to COVID-19 preventive measures}

158 DCWs scored high for adherence to COVID-19 preventive measures (total score $20.94 \pm 2.90$ ) and reported moderate difficulty in adhering to these measures (total score $2.33 \pm 1.17$ ) (Table 4). Among the difficulties encountered, 51\% respondents reported a lack of PPE, uncooperative patients (23.5\%), overcrowded medical facilities (19.1\%), and lack of COVID-19 prevention and control guidelines (16\%) (Table 4).

Table 4. Dental care workers adherence to COVID-19 preventive measures $(n=514)$

\begin{tabular}{|c|c|c|c|}
\hline \multicolumn{2}{|r|}{ Adherence to COVID-19 preventive measures } & $\mathbf{n}$ & $\%$ \\
\hline \multirow[b]{3}{*}{ Measures } & Wear PPE & 3.21 & $-4)$ \\
\hline & Use face mask correctly during patient care & 3.64 & $-4)$ \\
\hline & Practice hand hygiene correctly & 3.59 & $-4)$ \\
\hline \multirow{3}{*}{$\begin{array}{l}\text { Mean } \pm \text { SD } \\
(\text { Min-Max) }\end{array}$} & $\begin{array}{l}\text { Clean and disinfect surfaces in patient care areas } \\
\text { regularly }\end{array}$ & \multicolumn{2}{|c|}{$3.35 \pm 0.75(0-4)$} \\
\hline & Safe disposal of waste & \multicolumn{2}{|c|}{$3.61 \pm 0.59(0-4)$} \\
\hline & $\begin{array}{l}\text { Apply procedures to prevent all transmission routes } \\
\text { of COVID-19 }\end{array}$ & \multicolumn{2}{|c|}{$3.54 \pm 0.66(0-4)$} \\
\hline
\end{tabular}




\begin{tabular}{|c|c|c|c|}
\hline \multicolumn{2}{|c|}{ Adherence to COVID-19 preventive measures } & $\mathbf{n}$ & $\%$ \\
\hline & Total & \multicolumn{2}{|c|}{$\begin{array}{c}20.94 \pm 2.90(4- \\
24)\end{array}$} \\
\hline \multicolumn{2}{|c|}{$\begin{array}{l}\text { Difficulty to adhere to epidemic prevention measures } \\
\qquad \text { Mean } \pm \mathrm{SD} \text { (Min-Max) }\end{array}$} & \multicolumn{2}{|c|}{$2.33 \pm 1.17(1-5)$} \\
\hline \multirow{5}{*}{$\begin{array}{l}\text { Difficulties to } \\
\text { adhere to } \\
\text { preventive } \\
\text { measures }\end{array}$} & Lack of PPE at health facilities & 262 & 51.0 \\
\hline & Overcrowded health facilities & 98 & 19.1 \\
\hline & Patients do not cooperate & 121 & 23.5 \\
\hline & $\begin{array}{l}\text { Lack of guidelines on COVID-19 prevention and } \\
\text { control in medical facilities }\end{array}$ & 82 & 16.0 \\
\hline & Others & 12 & 2.3 \\
\hline
\end{tabular}

\subsection{Impact of COVID-19 on the quality of life of dental care workers}

167 Dental care workers income dramatically decreased due to the COVID-19 epidemic (4.04 \pm 1.15$)$; they were moderately and to very worried about their own health $(2.58 \pm 1.25)$ and the health of their relatives $(3.01 \pm 1.29)$ (Table 5). DCWs working time decreased significantly (68.9\%) (Table

Table 5. Impact of COVID-19 on the quality of life of dental care workers $(n=514)$

\begin{tabular}{|c|l|c|}
\hline \multirow{2}{*}{ Impact COVID-19 } & Fear and worry about respondents' health & $2.58 \pm 1.25(1-5)$ \\
\cline { 2 - 3 } & Fear and worry about their relatives' health & $3.01 \pm 1.29(1-5)$ \\
\cline { 2 - 3 } Mean \pm SD & Income decreased due to the impact of the & $4.04 \pm 1.15(1-5)$ \\
(Min-Max) & COVID-19 pandemic & $2.41 \pm 1.19(1-5)$ \\
\cline { 2 - 3 } & Difficulties in obtaining food & \\
\hline
\end{tabular}




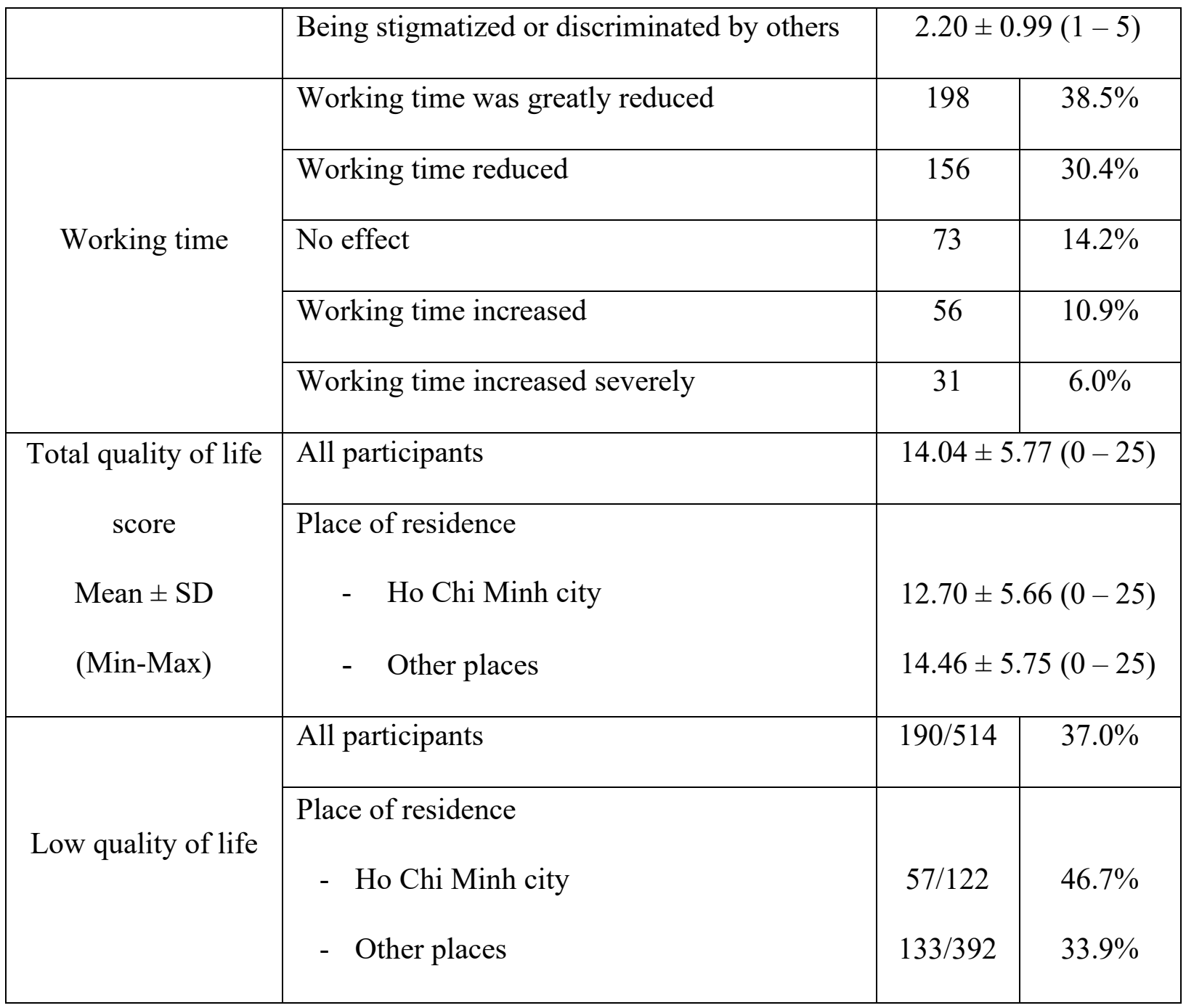

175 3.6. Factors associated with adherence to COVID-19 preventive measures by dental care workers

177 A higher quality-of-life score, COVID-19 infection prevention training, living in urban area, and 178 older age were factors positively associated with adherence to COVID-19 preventive measures. A 179 profession as a dentist, and lack of PPE at health facilities were factors negatively associated with 180 adherence to COVID-19 preventive measures. 
Table 6. Factors associated with adherence to COVID-19 preventive measures by dental care

workers* $(n=514)$

\begin{tabular}{|l|c|c|}
\hline \multicolumn{1}{|c|}{ Independent variables } & $\boldsymbol{\beta}(\mathbf{9 5 \%}$ CI) & p \\
\hline Gender: Male & $0.42(-0.11-0.94)$ & 0.118 \\
\hline Age & $0.03(0.00-0.06)$ & 0.048 \\
\hline Quality of life score & $0.06(0.02-0.10)$ & 0.008 \\
\hline Profession as dentist & $-0.85(-1.47--0.23)$ & 0.008 \\
\hline Currently living in urban area & $0.66(0.03-1.29)$ & 0.041 \\
\hline Trained in COVID-19 infection prevention skills & $0.58(0.04-1.12)$ & 0.035 \\
\hline Lack of PPE at health facilities & $-0.78(-1.29--0.27)$ & 0.003 \\
\hline
\end{tabular}

*Multivariable linear regression model. Dependent variable was the total score of adherences to

186 COVID-19 prevention measures by DCWs.

\section{4. Discussion}

In 2020, Vietnam was recognized worldwide to be extremely effective in fighting the COVID-19 pandemic. However, the COVID-19 virus is constantly evolving, and new mutations appear, threatening the control of the pandemic world-wide. Since April 2021, the Delta variant caused a large wave of infection in Ho Chi Minh City and many provinces in Vietnam [20].

During dental care, DCWs are at high risk of COVID-19 infection. Indeed, through the creation of saliva aerosols, pathogens will be dispersed from the oropharynx and oral cavity, and spread by air and by contaminating surfaces [21]. As such, it is necessary to train DCWs, on strict adherence to infection control practices (use of hand sanitizer, face masks, and maintaining social distancing measures), reduction of dental droplets, and ways to manage air quality in dental treatment rooms by reducing the use of air conditioners and improving air exchange [22,23]. However, $161(31.3 \%)$ of the 514 Vietnamese DCWs who participated in this survey did not receive training to improve 
their knowledge and skills concerning COVID-19 preventive measures. In an online survey in

201 China among orthodontists, orthodontic residents, and nurses, the majority of respondents

$202(80.2 \%)$ were confident that they had sufficient knowledge about COVID-19, but most of them

203 had less than half of the answers about COVID-19 correct [24]. The Vietnamese DCWs regularly

204 or always adhered to COVID-19 prevention measures, while, only $38.5 \%$ of dentists in 205 Balochistan (Pakistan) used N95 masks [25].

206 DCWs in Vietnam obtained information about the pandemic, from television and radio (81.5\%), 207 the website of the $\mathrm{MoH}$ (81.3\%), and social networks (86.8\%). In 2021 in Pakistan, sources of 208 COVID-19 information reported by DCWs included social networks (46.7\%), television (26.7\%), 209 newspapers (10.8\%) and other sources (15.8\%) [26]. In Australia, most dental students (89.6\%) received information about COVID-19 infection from official government sources [27]. In a study in India, $83 \%$ of dental students were considered to have adequate knowledge about COVID 19

212 and almost $80 \%$ reported to adhere to appropriate practices regarding COVID-19 [28].

213 In our study older age, better quality of life, living in an urban area, and training on COVID-19 214 prevention, were associated with better adherence to COVID-19 preventive measures. However, 215 dentists did adhere less optimal than other DCWs. In India it was reported that most dental 216 practitioners had a low level of knowledge (38.1\%), and no relationship was found between 217 professional experience and level of knowledge [29]. However, results from a multinational study 218 among DCWs documented an association between level of knowledge and experience about 219 COVID-19 and adherence to preventive measures [30,31]. A similar finding was also reported in a study among DCWs in Saudi Arabia [32].

221 Since the outbreak of the pandemic in Vietnam in April 2021, dentists faced many difficulties in 222 dealing with the pandemic. Therefore, it is necessary to provide sufficient protective equipment 223 in the dental treatment room, and update the prevention instructions for DCWs [24,25]. In Saudi 224 Arabia, dentists above the age of 45 years, and with longer working hours and years of experience 
significantly were more adherent to preventive measures [33]. In Vietnam people living in urban

226

227

228

229

230

231

232

233

234

235

236

237 areas were more adherent [34], perhaps because cities are the main places of outbreaks. In order to ensure social distancing, reduce the overload on tertiary hospitals and decrease the risk of infection, teledentistry should be used $[35,36]$.

Similar to what has been observed in other countries, the COVID-19 outbreak in Vietnam revealed the inadequate cooperation of pandemic-related health services and the insufficient access to PPE [37]. Attention should be paid to protect frontline health workers by providing PPE and continuous competence training [38]. Furthermore, dental care clinics must setup a patients classification system based on dental conditions, body temperature, and TOOC (travel history, occupation, contact history, and cluster history), and implement strict working procedures to prevent the spread of COVID-19 during dental treatment [39].

In total $390(75.9 \%)$ Vietnamese DCWs had received at least one dose of the COVID-19 vaccine but $24,1 \%$ were still unvaccinated. Of the unvaccinated, $52.4 \%$ were willing to be vaccinated, but $40.3 \%$ only wished to receive the vaccine they preferred. This rate of vaccine refusal among DCWs in Vietnam is low. In an Italian study, $18 \%$ of dentists opposed vaccination [40]. Only about $21 \%$ of Egyptian HCWs accepted to be COVID-19 vaccinated [41], In a survey in the United States, only $64.6 \%$ of medical professionals accepted the COVID-19 vaccine [42]. Immunization against COVID-19 protects against a deadly disease and also helps to create the herd immunity needed to control this pandemic [43].

Vaccination of DCWs should be a priority due to their high risks of infection. Compared to high income countries and certain other southeast Asian countries, Vietnam has a relatively low rate of vaccination against COVID-19. On September 11, 2021, Vietnam had injected more than 28 million doses of COVID-19 vaccine, of which nearly 23.2 million as a first dose (reaching $44.3 \%$ of the population aged 18 and above) and nearly 5.1 million as a second dose (reaching $9.5 \%$ of the population aged 18 and above) [44]. Thus, the proportion of adults that still need to be COVID- 
19 vaccinated is still large considering the target of herd immunity. However, it is expected that in $2022,70 \%$ of the population in Vietnam will be vaccinated with 2 doses of a COVID-19 vaccine [45].

In September 2021, data provided to WHO by 119 mainly high income countries, revealed that about $40 \%$ of all HCWs got a full dose of COVID-19 vaccination [46]. It is clear that more effort is needed to increase the COVID-19 vaccination rate among HCWs and to reduce vaccine hesitancy [47].

\section{Impact of COVID-19 pandemic on the lives of DCWs}

Due to the COVID-19 pandemic the income of the Vietnamese DCWs decreased dramatically, and DCWs experienced moderate to high level of anxiety concerning their own live and their relatives' live. In a cross-sectional online survey among 312 dentists from India, USA, UK and Iran, dentists reported that they suffered from stress and anxiety due to the shutdown of their private dental clinics; $72.5 \%$ were worried about financial loss during the COVID-19 pandemic, and $60 \%$ were worried about lack of PPE [48]. Thirty seven percent of the Vietnamese DCWs, considered their quality of life of low level of quality. This proportion was higher in Ho Chi Minh City, where the outbreak was most dramatic. A study on the COVID-19's impact on private practice and academic dentistry in North America highlighted the anxiety among DCWs due to the high risk of occupational infection [11]. A study in Pakistan found that $75 \%$ of dentists were afraid of being infected with COVID-19, and $80.9 \%$ wanted to close their dental care services

269 during the pandemic [25]. Similar to other countries, DCWs in Vietnam reported increased stress

270 because of the worsening of their financial situation due to the closure of dental care services, decreased number of clients and the rising cost of services [37,49].

272 World-wide the COVID-19 pandemic increased the rates of anxiety and depression among HCWs

273 [50]. While HCWs play an important role in limiting the impact of COVID-19, their lives have 274 been greatly affected by the pandemic [51]. Therefore, efforts are needed to improve their quality 
275 of life by minimizing the stress and psychological sequelae associated with COVID-19 and by

276 improving social support [52].

277 To prevent COVID19 transmission among DCWs and HCW in general, a comprehensive 278 approach of combining vaccination, training on prevention skills, and psycho-social support at 279 health facilities will need to be implemented [47].

\section{Limitations}

281 This study has several limitations. A relatively large number of DCWs in Vietnam did not 282 participate in the survey and this creates a selection bias. Recall bias is a possibility when 283 participants were asked to recall events from the past. Moreover, online data collection may lead 284 to errors because participants may not have understood the questions. However, to avoid this we created a hotline where participants were able to contact us for more explanations.

\section{Conclusions}

287 Most Vietnamese DCWs do adhere to COVID-19 prevention measures. However insufficient access to PPE remains a problem. Their quality of life is affected, especially in Ho Chi Minh city, the site in Vietnam most affected by the pandemic. The impact of the pandemic on the physical and mental health of the DCWs is significant. Therefore, policies are needed to support DCWs, to ensure their physical and mental well-being.

Funding: This study received small financial support from Faculty of Odonto-Stomatology, University of Medicine and Pharmacy, Hue University and the Global Health Institute, University of Antwerp, Antwerp, Belgium (R Colebunders received funding from VLIRUOS).

Acknowledgements: We would like to express our sincere thanks to the staff of the Faculty of 298 Odonto-Stomatology, Hue University of Medicine and Pharmacy for their help in the initial phase 
299 of the study. Our sincere thank also goes to all the dentists, nurses, technicians who participated 300 in the survey.

301

302 Authors' contributions: Conceptualization and methodology, T.T.T, T.V.V; Statistical analysis, 303 interpretation, data and drafting, T.T.T, T.V.V, and T.D.H; Questionnaire adaptation and data collection, M.V.H and N.T.Q.T; Critically revised the draft manuscript, T.V.V, T.T.T, R.C, T.D.H, M.V.H, and N.T.Q.T; All authors have read and approved the final manuscript.

Institutional Review Board Statement: Anonymity and informed consent were assured. The study was conducted according to the guidelines of the Declaration of Helsinki, and approved by the Ethical Review Committee of Hue University of Medicine and Pharmacy, Vietnam (No. H2021/418, signed on August $\left.6^{\text {th }}, 2021\right)$.

Informed Consent Statement: The consent form was displayed to the participants before starting

313 the survey. The questionnaire was only available for a response when participants read the agreements on this form and selected "agree" in the checkbox.

Data Availability Statement: All answers were collected anonymously and stored in Microsoft

317 Form application. The datasets created and/or analyzed during the current study are available from 318 the corresponding author upon reasonable request.

320 Conflicts of Interest: The authors declare no conflict of interest. The sponsors had no role in the design, execution, interpretation, or writing of the study. 
COVID-19: Coronavirus disease 2019

325 DCWs: Dentalcare workers

326 HCWs: Healthcare workers

327 PPE: Personal protective equipment

328 SARS-CoV-2: Severe acute respiratory syndrome coronavirus 2

329 SD: Standard deviation

330 WHO: World Health Organisation

331

\section{REFERENCES}

333 1. World Health Organization. Coronavirus disease 2019 (COVID-19) Situation Report - 51; $334 \quad 11$ March 20202020.

335 2. World Health Organization. Weekly Operational Update on COVID-19, Issue No. 78; 3 $336 \quad$ November 20212021.

337 3. Vietnam Ministry of Health. News page about COVID-19 acute respiratory infection updated 338 on October 3, 2021. Available online: https://covid19.gov.vn/big-story/cap-nhat-dien-bien339 dich-covid-19-moi-nhat-hom-nay-171210901111435028.htm (accessed on October 3, 2021).

340 4. World Health Organization. The impact of COVID-19 on health and care workers: a closer 341 look at deaths. Health Workforce Department - Working Paper 1; Geneva, September 2021

343 5. Gómez-Ochoa, S.A.; Franco, O.H.; Rojas, L.Z.; Raguindin, P.F.; Roa-Díaz, Z.M.; 344 Wyssmann, B.M.; Guevara, S.L.R.; Echeverría, L.E.; Glisic, M.; Muka, T. COVID-19 in 345 Health-Care Workers: A Living Systematic Review and Meta-Analysis of Prevalence, Risk 346 Factors, Clinical Characteristics, and Outcomes. American Journal of Epidemiology 2020, 190, 161-175, doi:10.1093/aje/kwaa191. 
6. Kim, H.; Hegde, S.; LaFiura, C.; Raghavan, M.; Sun, N.; Cheng, S.; Rebholz, C.M.; Seidelmann, S.B. Access to personal protective equipment in exposed healthcare workers and COVID-19 illness, severity, symptoms and duration: a population-based case-control study in six countries. BMJ global health 2021, 6, doi:10.1136/bmjgh-2020-004611.

7. Gold, J.A. Covid-19: adverse mental health outcomes for healthcare workers. BMJ (Clinical research ed.) 2020, 369, m1815, doi:10.1136/bmj.m1815.

8. Nguyen, N.P.T.; Le, D.D.; Colebunders, R.; Siewe Fodjo, J.N.; Tran, T.D.; Vo, T.V. Stress and Associated Factors among Frontline Healthcare Workers in the COVID-19 Epicenter of Da Nang City, Vietnam. Int $J$ Environ Res Public Health 2021, 18, 7378, doi:10.3390/ijerph18147378.

9. Meng, L.; Hua, F.; Bian, Z. Coronavirus Disease 2019 (COVID-19): Emerging and Future Challenges for Dental and Oral Medicine. Journal of dental research 2020, 99, 481-487, doi:10.1177/0022034520914246.

10. Peng, X.; Xu, X.; Li, Y.; Cheng, L.; Zhou, X.; Ren, B. Transmission routes of 2019-nCoV and controls in dental practice. International Journal of Oral Science 2020, 12, 9, doi:10.1038/s41368-020-0075-9.

11. Wu, K.Y.; Wu, D.T.; Nguyen, T.T.; Tran, S.D. COVID-19's impact on private practice and 365 academic dentistry in North America. Oral Dis 2021, 27 Suppl 3, 684-687, doi:10.1111/odi.13444.

12. Odeh, N.D.; Babkair, H.; Abu-Hammad, S.; Borzangy, S.; Abu-Hammad, A.; Abu-Hammad, O. COVID-19: Present and Future Challenges for Dental Practice. Int J Environ Res Public Health 2020, 17, doi:10.3390/ijerph17093151. in the context of COVID-19; 2020. 
14. American Dental Association. ADA interim guidance for minimizing risk of COVID-19 transmission. United States of America 2020.

15. Vietnam Ministry of Health. Decision on promulgating the Guidance on prevention and control of COVID-19 in medical examination and treatment establishments, December 14, 2020, No. 5188/QD-BYT. 2020.

16. Vietnam Ministry of Health. Guidelines for prevention and control of acute respiratory infections caused by Corona virus 2019 (COVID-19) in medical examination and treatment premises 2020-02-19, No. 468/QD-BYT. 2020.

17. McLeod, S.A. Likert scale. Simply Psychology. Available online: https://www.simplypsychology.org/likert-scale.html (accessed on September 12, 2021).

18. Topp, C.W.; Østergaard, S.D.; Søndergaard, S.; Bech, P. The WHO-5 Well-Being Index: a systematic review of the literature. Psychotherapy and psychosomatics 2015, 84, 167-176, doi:10.1159/000376585.

19. Psychiatric Research Unit - WHO Collaborating Center for Mental Health. WHO (Five) WellBeing Index (1998 version); Psychiatric Research Unit, WHO Collaborating Center for Mental Health, Frederiksborg General Hospital: Hillerod, Denmark, 1998.

20. The-Phuong Nguyen; Zoie SY Wong; Lin Wang; Truc Thai Thanh; Huy Van Nguyen; Stuart Gilmour. Rapid impact assessments of COVID-19 control measures against the Delta variant and short-term projections of new confirmed cases in Vietnam. Journal Of Global Health 2021, 11, doi: doi: 10.7189/jogh.11.03118.

21. Patel, M. Infection control in dentistry during COVID - 19 pandemic: what has changed? Heliyon 2020, 6, e05402, doi:10.1016/j.heliyon.2020.e05402.

22. Jiang, C.M.; Duangthip, D.; Auychai, P.; Chiba, M.; Folayan, M.O.; Hamama, H.H.H.; Kamnoedboon, P.; Lyons, K.; Matangkasombut, O.; Mathu-Muju, K.R.; et al. Changes in 
Oral Health Policies and Guidelines During the COVID-19 Pandemic. Frontiers in Oral Health 2021, 2, doi:10.3389/froh.2021.668444.

398

23. Amato, A.; Caggiano, M.; Amato, M.; Moccia, G.; Capunzo, M.; De Caro, F. Infection Control in Dental Practice During the COVID-19 Pandemic. Int J Environ Res Public Health 2020, 17, doi:10.3390/ijerph17134769.

24. Hua, F.; Qin, D.; Yan, J.; Zhao, T.; He, H. COVID-19 Related Experience, Knowledge, Attitude, and Behaviors Among 2,669 Orthodontists, Orthodontic Residents, and Nurses in China: A Cross-Sectional Survey. Frontiers in Medicine 2020, 7, doi:10.3389/fmed.2020.00481.

25. Kamran, R.; Saba, K.; Azam, S. Impact of COVID-19 on Pakistani dentists: a nationwide cross sectional study. BMC Oral Health 2021, 21, 59, doi:10.1186/s12903-021-01413-6.

26. Aslam B; Basheer K; Yasir M; Faiz M. Analysis of Knowledge for Prevention of COVID-19 Infection Among Dental Practitioners. Sys Rev Pharm 2021, 12, 187-189.

27. Boukhobza, S.; Ritschl, V.; Stamm, T.; Bekes, K. The COVID-19 Pandemic and Its Impact on Knowledge, Perception and Attitudes of Dentistry Students in Austria: A Cross-Sectional Survey. J Multidiscip Healthc 2021, 14, 1413-1422, doi:10.2147/JMDH.S311535.

28. Batra, K.; Urankar, Y.; Batra, R.; Gomes, A.F.; S, M.; Kaurani, P. Knowledge, Protective Behaviors and Risk Perception of COVID-19 among Dental Students in India: A CrossSectional Analysis. Healthcare 2021, 9, 574.

29. Singh Gambhir, R.; Singh Dhaliwal, J.; Aggarwal, A.; Anand, S.; Anand, V.; Kaur Bhangu, A. Covid-19: a survey on knowledge, awareness and hygiene practices among dental health professionals in an Indian scenario. Roczniki Panstwowego Zakladu Higieny 2020, 71, 223229, doi:10.32394/rpzh.2020.0115.

30. Kamate, S.K.; Sharma, S.; Thakar, S.; Srivastava, D.; Sengupta, K.; Hadi, A.J.; Chaudhary, A.; Joshi, R.; Dhanker, K. Assessing Knowledge, Attitudes and Practices of dental 
practitioners regarding the COVID-19 pandemic: A multinational study. Dental and medical problems 2020, 57, 11-17, doi:10.17219/dmp/119743.

423

424

425

426

427

428

429

430

431

432

433

434

435

436

437

438

439

440

441

442

443

444

445

31. Sezgin, G.P.; ŞirinoĞlu Çapan, B. Assessment of dentists' awareness and knowledge levels on the Novel Coronavirus (COVID-19). Brazilian oral research 2020, 34, e112, doi:10.1590/1807-3107bor-2020.vol34.0112.

32. Srivastava, K.C.; Shrivastava, D.; Sghaireen, M.G.; Alsharari, A.F.; Alduraywish, A.A.; AlJohani, K.; Alam, M.K.; Khader, Y.; Alzarea, B.K. Knowledge, attitudes and practices regarding COVID-19 among dental health care professionals: a cross-sectional study in Saudi Arabia. J Int Med Res 2020, 48, 300060520977593 , doi:10.1177/0300060520977593.

33. Al-Khalifa, K.S.; AlSheikh, R.; Al-Swuailem, A.S.; Alkhalifa, M.S.; Al-Johani, M.H.; AlMoumen, S.A.; Almomen, Z.I. Pandemic preparedness of dentists against coronavirus disease: A Saudi Arabian experience. PLOS ONE 2020, 15, e0237630, doi:10.1371/journal.pone.0237630.

34. Nguyen, N.P.T.; Hoang, T.D.; Tran, V.T.; Vu, C.T.; Siewe Fodjo, J.N.; Colebunders, R.; Dunne, M.P.; Vo, T.V. Preventive behavior of Vietnamese people in response to the COVID19 pandemic. PLOS ONE 2020, 15, e0238830, doi:10.1371/journal.pone.0238830.

35. Bastani, P.; Mohammadpour, M.; Ghanbarzadegan, A.; Kapellas, K.; Do, L. Global concerns of dental and oral health workers during COVID-19 outbreak: a scope study on the concerns and the coping strategies. Systematic Reviews 2021, 10, doi:10.1186/s13643-020-01574-5.

36. Bhanushali, P.; Katge, F.; Deshpande, S.; Chimata, V.K.; Shetty, S.; Pradhan, D. COVID-19: Changing Trends and Its Impact on Future of Dentistry. International journal of dentistry 2020, 2020, 8817424, doi:10.1155/2020/8817424.

37. Tysiąc-Miśta, M.; Dziedzic, A. The Attitudes and Professional Approaches of Dental Practitioners during the COVID-19 Outbreak in Poland: A Cross-Sectional Survey. Int J Environ Res Public Health 2020, 17, 4703, doi:10.3390/ijerph17134703. 
38. Boti Sidamo, N.; Hussen, S.; Shibiru, T.; Girma, M.; Shegaze, M.; Mersha, A.; Fikadu, T.; Gebru, Z.; Andarge, E.; Glagn, M.; et al. Exploring Barriers to Effective Implementation of Public Health Measures for Prevention and Control of COVID-19 Pandemic in Gamo Zone of Southern Ethiopia: Using a Modified Tanahashi Model. Risk Manag Healthc Policy 2021, 14, 1219-1232, doi:10.2147/RMHP.S297114.

39. Lee, Y.-L.; Chu, D.; Chou, S.-Y.; Hu, H.-Y.; Huang, S.-J.; Yen, Y.-F. Dental care and infection-control procedures during the COVID-19 pandemic: The experience in Taipei City Hospital, Taiwan. J Dent Sci 2020, 15, 369-372, doi:10.1016/j.jds.2020.05.011.

40. Belingheri, M.; Roncalli, M.; Riva, M.A.; Paladino, M.E.; Teruzzi, C.M. COVID-19 vaccine hesitancy and reasons for or against adherence among dentists. Journal of the American Dental Association (1939) 2021, 152, 740-746, doi:10.1016/j.adaj.2021.04.020.

41. Fares, S.; Elmnyer, M.M.; Mohamed, S.S.; Elsayed, R. COVID-19 Vaccination Perception and Attitude among Healthcare Workers in Egypt. Journal of Primary Care \& Community Health 2021, 12, 21501327211013303 , doi:10.1177/21501327211013303.

42. Dowdle, T.S.; Dennis, J.; Nugent, K.M.; Byrd, T. Intention to Receive COVID-19 Vaccine by U.S. Health Sciences University Employees. J Prim Care Community Health 2021, 12, 21501327211036611 , doi:10.1177/21501327211036611.

43. World Health Organization. Coronavirus disease (COVID-19): Herd immunity, lockdowns and COVID-19, 31 December 2020. Available online: https://www.who.int/news-room/q-adetail/herd-immunity-lockdowns-and-covid-19 (accessed on September 12, 2021).

44. Vietnam Ministry of Health Portal. September 12: 11,478 COVID-19 new cases, Ho Chi Minh City and Binh Duong alone recorded nearly 9,350 cases. Available online: https://moh.gov.vn/tin-lien-quan/-/asset_publisher/vjYyM7O9aWnX/content/ngay-12-9them-11-478-ca-mac-covid-19-rieng-tp-hcm-va-binh-duong-ghi-nhan-gan-9-350-ca (accessed on 12/09/2021). 
45. Vietnam Ministry of Health. Decision on the issuance of the implementation plan for the COVID-19 vaccination campaign in 2021-2022. 2021, 3355/QD-BYT.

46. World Health Organization. WHO and partners call for action to better protect health and care workers from COVID-19. Available online: https://www.who.int/news/item/21-102021-who-and-partners-call-for-action-to-better-protect-health-and-care-workers-fromcovid-19 (accessed on 21 October 2021).

47. Le, X.T.T.; Nguyen, Q.T.; Onyango, B.; Nguyen, Q.N.; Pham, Q.T.; Ta, N.T.K.; Nguyen, T.T.; Le, H.T.; Vu, L.G.; Hoang, M.T.; et al. Perception Toward Exposure Risk of COVID19 Among Health Workers in Vietnam: Status and Correlated Factors. Frontiers in public health 2021, 9, 589317, doi:10.3389/fpubh.2021.589317.

48. Gupta, S.; Gupta, R.; javadi, h.; Ravikumar, S.; Gupta, S. Challenges faced by dental professionals during COVID-19-A cross sectional survey. Journal of Advances in Internal Medicine 2020, 9, 60-64, doi:10.3126/jaim.v9i2.32816.

49. Coulthard, P.; Thomson, P.; Dave, M.; Coulthard, F.P.; Seoudi, N.; Hill, M. The COVID-19 pandemic and dentistry: the clinical, legal and economic consequences - part 2: consequences of withholding dental care. British Dental Journal 2020, 229, 801-805, doi:10.1038/s41415020-2406-9.

50. Faria de Moura Villela, E.; Rodrigues da Cunha, I.; Nelson Siewe Fodjo, J.; Obimpeh, M.; Colebunders, R.; Van Hees, S. Impact of COVID-19 on Healthcare Workers in Brazil between August and November 2020: A Cross-Sectional Survey. Int J Environ Res Public Health 2021, 18, doi:10.3390/ijerph18126511.

51. Pacutova, V.; Madarasova Geckova, A.; Kizek, P.; F. de Winter, A.; A. Reijneveld, S. The Impact of Pandemic Management on the Quality of Life of Slovak Dentists. Int J Environ Res Public Health 2021, $18,5484$. 
495 52. Woon, L.S.-C.; Mansor, N.S.; Mohamad, M.A.; Teoh, S.H.; Leong Bin Abdullah, M.F.I. 496 Quality of Life and Its Predictive Factors Among Healthcare Workers After the End of a 497 Movement Lockdown: The Salient Roles of COVID-19 Stressors, Psychological Experience, 498 and Social Support. Frontiers in Psychology 2021, 12, doi:10.3389/fpsyg.2021.652326.

499

500 